\title{
Increased Physis Thickness
}

National Cancer Institute

\section{Source}

National Cancer Institute. Increased Physis Thickness. NCI Thesaurus. Code C139154.

An increase in the dimension between the two surfaces, in comparison to a standard or norm. 